ISSN 2691-2260 (Online)

\title{
New Florida Journal of Anthropology
}

Volume 1 Issue 1

July 2020

A publication of the Department of Anthropology and George A. Smathers Libraries of the University of Florida.

\section{Editorial Board}

Coordinating Editor

Biological Anthropology Editor

Archaeology Editor

Sociocultural Editor

Faculty Advisor
Megan Hanna Fry

Samantha McCrane

Brittany Mistretta

Christopher LeClere

Ginessa Mahar

Cover Design: by Ayelen Garcia-Rudnik. A fragment of a ceramic artifact found in the Mochena Borago archeological site and rock shelter on the side of the dormant volcano of Mt. Damota in the southwestern highlands of Ethiopia. This project is concentrated primarily on the site's late Pleistocene deposits and has provided the first securely dated archeological collection for the later periods of dispersal from Africa. The most abundant artifacts discovered were obsidian artifacts. Directed by Dr. Steven Brandt, the University of Florida's Southwest Ethiopia Archeological Project (SWEAP) annually hosts students in this 6-week field program. This photograph was taken during the 2017 field season.

\section{Contact:}

mailto:nfja@anthro.ufl.edu

journals.flvc.org/NFJA

nfjanthro.wordpress.com

Twitter@AnthroNfj

Instagram@nfjanthro

Facebook

@NewFloridaJournalofAnthropology

\section{Mailing Address:}

New Florida Journal of Anthropology

Department of Anthropology

University of Florida

Turlington Hall, Room 1112

PO Box 117305

Gainesville, Florida 32611-7305

USA

Copyright Notice: Authors retain copyright to their publications. 